his patient. His practice must be governed by the recognition of the possible consequences that may follow.

If not warned by his own observation, he should be forewarned by the researches and observations of others. I have been cognizant of numerous instances of disaster in all of the mechanical methods I have mentioned, and many deaths have resulted from the employment of some of them. These untoward cases are usually not published. They ought to be published, however, as danger-signals to warn the unwary of the hazards that beset their paths.

As the main object I had in view in writing this paper was to caution my associates against the dangers of converting a chronic pelvic inflammation into a disastrous acute form, I desire to append a summary of suggestions and inferences drawn from it.

I. The sometimes terrible effects of examinations or operations in the pelvis do not often, if ever, take place when there is not a perceptible predisposing inflammation.

2. The inflammation may be so slight as to be easily overlooked.

3. It may be an original condition; the sequence of an acute attack long gone by, or it may be the product of some immediately previous examination or operation, the effects of which have not subsided.

4. T'o avoid the dangers of acute inflammation we should, in making a first examination for pelvic disease, conduct it in such a way as not to give the patient much pain, and when she complains of much suffering desist at the sacrifice of completeness of diagnosis.

5. Complaints of much tenderness to the touch, or the use of instruments; especially parous women, is sufficiently diagnostic of inflammation upon which to base treatment for that condition.

6. If, with such tenderness, a thorough examination or an operation is imperative, it should be done under profound anæsthesia. There is no question, in my mind, that much less danger of ill effects is incurred in making examinations or operations on susceptible subjects, under the free use of anæsthetics.

7. Examinations or operations should not be repeated until the effects of the first have entirely passed off.

8. As chronic parametritis is a frequent complication of most of the morbid conditions of the uterus it should be always suspected and its diagnosis be carefully considered in all cases of metritis.

9. When chronic parametritis is present it should be the chief, if not the exclusive object of treatment until removed.

10. It is not safe to use the sound, sponge-treatment, or intrauterine stem when there is perimetric inflanmation.

I I. It is especially dangerous to replace a displaced uterus, when it is bound down by inflammatory adhesions, by any means which will overcome its fixedness by force.

I 2. The use of pessaries or supports of any kind which find their lodgement in the pelvis is generally followed by disastrous consequences when there is even slight primitive inflammation.
I3. All local treatment of the uterus must be conducted with the greatest care in all cases where this complication is present.

\section{FRACTURES OF THE LONG BONES.}

BY JAMES R. TAYLOR, M.D., NEW YORK.

[Read before the Surgical Section of the American Medical Association, at the meeting in Cleveland, June 6,1883 .]

Mr. Chairman and Gentlemen:

In the limited time at my disposal I must greatly abbreviate the matter which I had prepared to offer on this occasion. I may claim, therefore, that it will not be possible for me to do justice either to my subject or to myself while omitting such large portions of a paper, which, in the nature of things, should have been presented as a whole. I will try, however, to lay before you as briefly as possible a few of the methods of diagnosis and treatment of fractures of the long bones, which have gradually taken present form in my hands during many years of extensive practice in this class of injuries as a surgeon to the "Out Door Dept. of Bellevue Hospital." I offer no apology for the crudeness or simplicity of some of the methods and appliances which I present-merely stating that with but a few hours for each clinic, and with thirty or forty patients in the ante-room clamoring for admittance to the surgery-and being butscantily furnished with necessary supplies, I seldom have either time or material tor refinements; but must get down to business. What to do must be decided promptly. Dressings must be applied quickly, and in a sufficiently substantial and economical manner to suit the case in the circumstances. Therefore, my constant aim is to simplify my work both as to the time occupied and the expense involved. Hippocrates, in his work on fractures, says "There is no necessity for much study to set a broken bone. Any ordinary physician can perform it." And my respect for and confidence in the utterance of this "shade of the mighty dead" is exhibited in the fact that, I a very ordinary physician, am very often attempting to do it.

He does not mention the necessity for a thorough knowledge of anatomy both general and regionala good general knowledge of both ancient and contemporaneous mechanico-therapeutics-a good degree of manual dexterity, together with a carefully cultivated discrimination, to enable the doctor to select or invent as the occasion requires-the mechanical means which will secure the greatest advantage to his patient with the minimum of suffering or inconvenience.

He may have assumed that the ordinary physician of our day would be possessed of all these advantages and would not require to be reminded of qualifications of such obvious necessity. And, Mr. Chairman, I think I may assume that, as I have the honor to address, probably the largest and surely the most distinguished body of surgeons ever assembled on the American continent, it will not be necessary, in my humble contribution to practical surgery, that I should enter into and discuss at any length matters of common detail which they all so well understand, or that 
I should elaborate every idea to which I may give utterance, or that I should give attention to special conditions or peculiarities of cases. I will also assume that you will justify me in confining myself entirely to methods of diagnosis, which I have thoroughly tested, and to the exhibition and description of the mechanico-therapeutical appliances, also thoroughly tested in my own experience, which I am about to offer for your inspection and consideration. Without wasting the brief time allotted to me in quoting authorities, or in offering opinions of the methods of other more eminent surgeons whose lives and energies have been devoted to the development and improvement of means for the alleviation of human suffering, whether or not those means shall in all cases meet my approval.

But while I wish to abstain from criticising the methods of other surgeons, I can hardly avoid making a remark in this place in reference to the apparatus which is now so commonly used by the profession for producing extension in the treatment of fractures of the femur, viz., the weight and pulley. It has no doubt been very useful in a great number of cases, and it seems to have received the endorsement of many of the writers of our modern text books. But I do not think that any surgeon can accept it as an instrument in all respects suitable for the purpose.

Of course it will produce extension as we apply it, but it is by the clumsiest means known in mechanics. And if an ordinary workman were to present me with such a device for the accomplishment of any important mechanical end, I should conclude that he was a man of but very limited resources, as there are very many far more elegant, and at the same time equally efficient, means within the range of common mechanical science which can be applied for the purpose. This leads me to the few remarks which I have to make on the

TREATMENT OF FRACTURES OF THE FEMUR, ILLUSTRATED BY PLATES III., IV. AND V.

I will not trouble you with the methods of making diagnosis in the fractures of this bone, as there are so many situations in which fractures may occur. And these may be also so different in character that it would require too much time. Then, too, the diagnosis in most of them is made sufficiently clear by the deformity, and by the false motion and other symptoms that I will entirely omit what I would like to say on that branch of the subject, and come at once to the treatment, selecting for my present purpose a simple fracture of the middle third of the bone.

I do this the more willingly, as the principles upon which the various fractures of this bone are treated are nearly identical. And as these principles, as far as I know, had their first recognition in the good old days of Hippocrates, and perhaps chiefly by that gentleman himself, they will require neither apology nor endorsement at my hands. Extension, coaptation and fixation has been the surgeon's motto ever since his day. It is his motto still, and it will continue to be his motto while fracturable bones form the framework of animal structures.

All our inventions and improvements are limited, therefore to mere details of apparatus, and their methods of application for the accomplishment of these necessary steps to the restoration to usefulness of a limb, by the cure of the lesion which we are

\section{Plate III.}

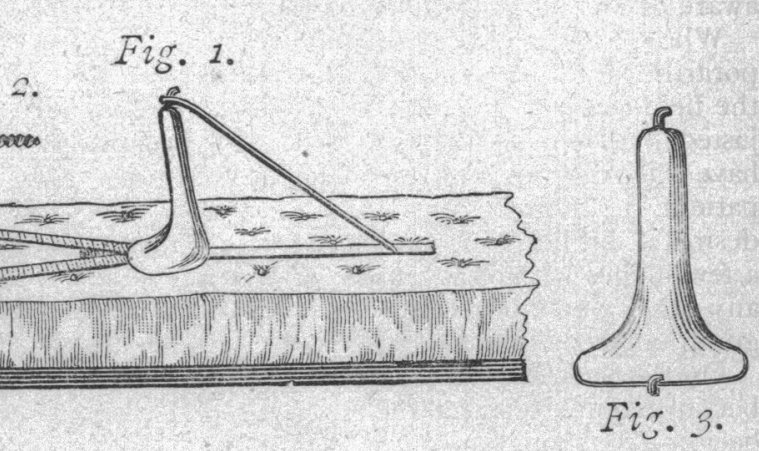

Fig. 1.-Shows saddle-brace, bedplate, and girth web-straps, in position on bed.

Fig. 2.-Screw-buckle.

FrG. 3.-Saddle.

considering. If you will look at plate III. of the engravings, with which you are supplied, you will see that it represents a good bed of any ordinary kind. It stands level on the floor, that is to say, the foot posts are not raised upon blocks to produce counterextension. This being to my mind a most objectionable method for obvious reasons, especially if we have a stout plethoric subject on our hands for treatment. Figure I. Upon the bed represents a nicely padded saddle, so constructed and arranged that its base projects under the nates of the patient, the wings resting against the well-cushioned tuberii ischii, while the upright body rests against the perinæum, fitting the parts nicely.

This saddle is maintained in a vertical position by an iron brace, with an eye at one end, which fits into a hole in one end of a bedplate of hoop iron covered with cloth. On the bottom of the saddle there is also a hook for attachment to the other end of the bedplate. When these parts are in their places, the saddle is in the position shown in the engraving. Attached to the bedplate, right under the base of the upright saddle, there are two pieces of girth-web, the free ends of which are made fast to buckles, which are provided with stems for screwing into the headboard of the bed-one on each side-or the girthwebs may be simply tied to the bed posts.

This saddle when thus placed in the position indicated, with its brace and bedplate in proper relations to it, together with the girth-web straps and screw- 
buckles or other means of attachment to the bedhead, is the means by which I make my counterextension in this fracture.

It will be readily seen that the amount of traction which this apparatus will resist is only limited by the strength of the materials employed in making it, and the endurance of the muscles of the patient. It certainly will resist far more extension force than a prudent surgeon would think it necessary to employ for the purpose he has in view. The efforts of the surgeon in the use of extension, being directed merely to restoring the limb to its normal length, by overcoming unnatural muscular contraction, and not to stretching the limb beyond that point, as he is well aware of the danger attending such procedure.

When it is necessary to remove the saddle temporarily the brace is lifted, and the saddle falls and the bedplate can be pulled to one side. It is readjusted with equal facility. With this apparatus we have a fixed point to resist the extension force. The patient lies comfortably on a level bed, and if he desires it, his head and shoulders may even be elevated a few inches without retarding the progress of, or in any other way interfering with the repairative process going on in the bone.

of the saddle, the parts subjected to its contact become quite tolerant in a very short time. An occasional sponging with alcohol and water, or the placing of a cool fresh towel, however, will be found comforting and grateful. I may mention here that this method of counter-extension is equally

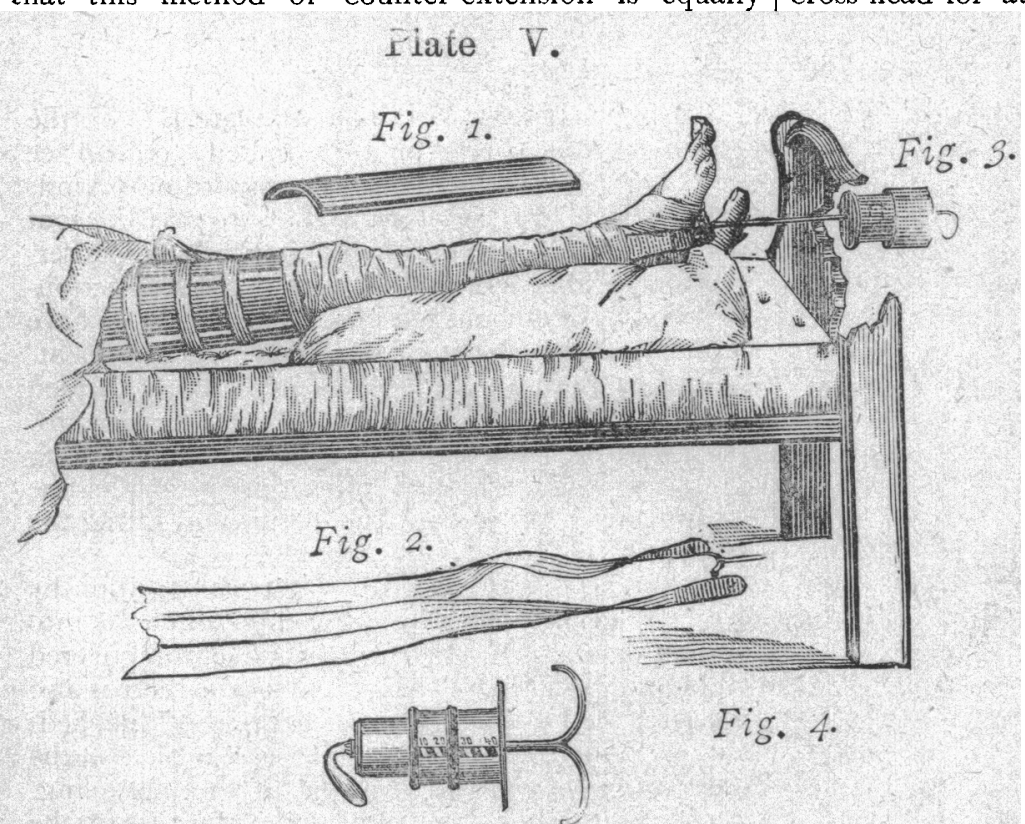

FIG. 1.-Coaptation splint.

FIG. 2.-Adhesive side plasters.

Fic. 3.-Extension foot spring.

Fig. 4.-Extension foot spring enlarged. useful in intracapsular fracture, also in diseases of the hip or knee-joint, or wherever counter-extension of the limb is indicated. Combined with this apparatus there are many methods for producing extension. Elastic bands of rubber and other forms of rubber can be made to suit nicely, especially where children are the patients. Modes of application will suggest themselves to any surgeon.

I have also used coiled springs attached to my webbing straps, under the pillow at the bed-head, while the foot of the patient is attached to a hook in the foot-board, stretching these springs sufficiently to obtain the desired amount of extension and securing them to the bed-posts by leather straps. I invented, however, some time since a little extension apparatus which suits the purpose better than anything I have yet seen. Plate V., Fig. 3 and 4 . It consists of a coiled spring enclosed in a metal case. One end of the case slides into the other like a telescope tube. The large end is provided with a flange for fastening to the outside of the foot-board. This end of the case is also fenestrated, so that the action of the spring can be seen from without. On the edge of the fenestra there are figures to indicate pounds weight, and a projection on the edge of the inner tube serves as a pointer so that the amount of force required to shorten the case by pushing or pulling the inner part into the outer part is registered. Looking at Fig. 4 you will see that a stem passes through the case, the inside end of which has a cross-head for attachment to the patient by the adhesive side plasters, Fig. 2, the outer end of the stem terminates in a handle. This part of the stem screws into the other part, and is shortened or lengthened at pleasure by turning the handle. By this means the spring is compressed or lengthened so that the exact amount of extension force required in the case can be obtained simply by turning the handle backwards or forwards. Plate IV shows the method of extension by weight and pulley combined with my method of counter-extension by the saddle. The engraving will be easily understood.

As you see in Plates IV and V, the patient is represented as lying on the bed with the dressing completed. Fig. I in each plate represents a coaptation splint. This splint is made of what is called Holley's felt-after the inventor. It is made of various thicknesses, and is a very good article for the purpose, as it can be nicely moulded to fit the limb. I use four of these splints nicely padded. Their position is seen in the engravings.

-To keep these splints in place, $\mathrm{I}$ use four garter bands made of 


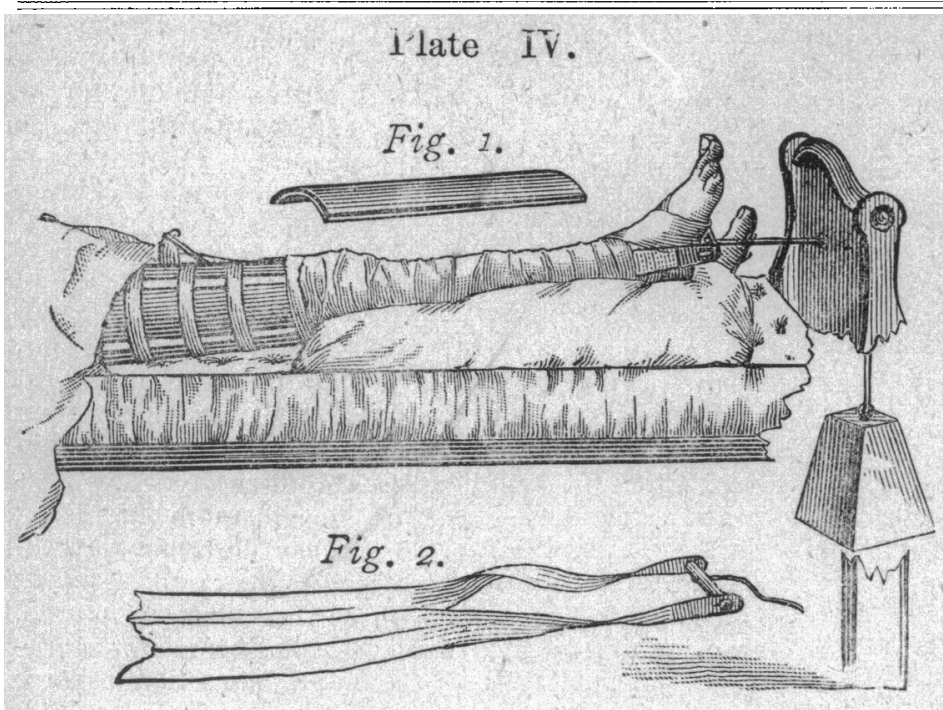

Fig. 1.-Coaptation splint.

Fig. 2 -Adhesive side plastcrs.

elastic similar to but stronger than that used in making gentlemens' suspenders. Plate VI, Fig. 4. These, in the first place, keep the splints firmly applied, and also, they being adjusted so that they retain a small amount of unexpended contractility, keep up equable pressure during the progress of the atrophy of the soft tissues. I am not

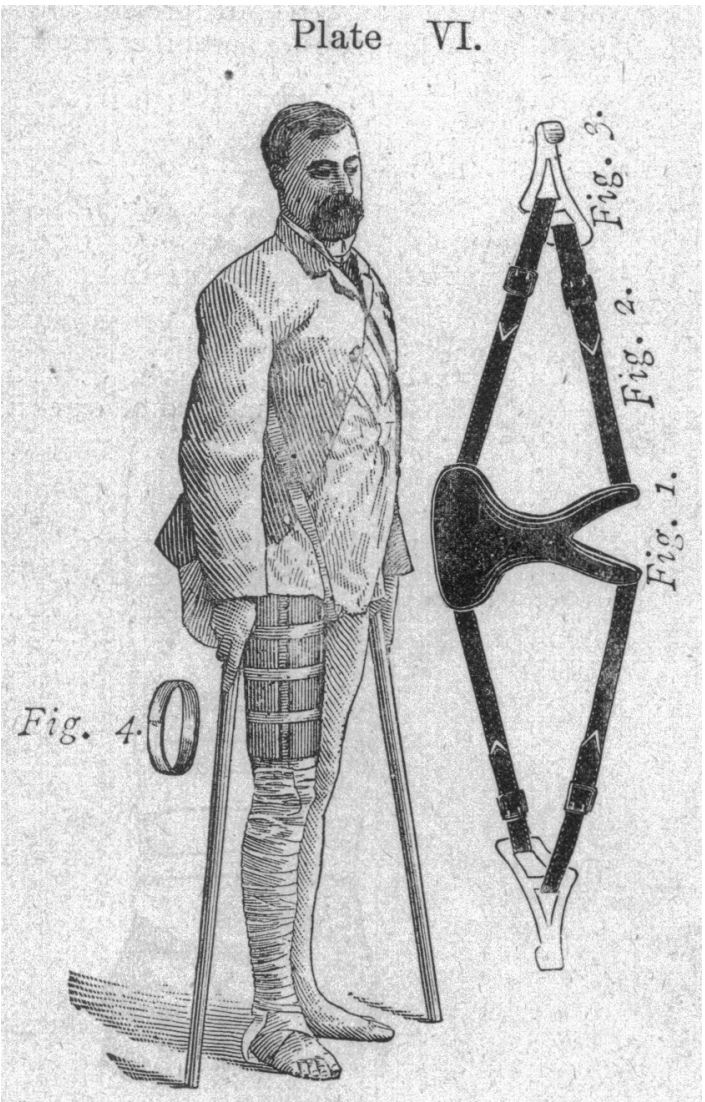

insensible to the possibility of mischief following the use of such elastic pressure, if placed carelessly or too tightly upon the limb. I think, however, that no careful surgeon would need to be warned that ligating the limb by any means whatever would be dangerous practice. I will say here, that my own views on the subject of coaptation splints in this or any other fracture of the long bones are very simple. The true splint for a broken bone is the periosteum and the surrounding soft tissues. And if the surgeon keeps in view the fact that the result of his extension and counter-extension, if wisely and effectively applied, is to restore these tissues to their original relations, re-establishing the normal form of the canal in which the bone lies, and that when this has been effected by the application of sufficient force for the purpose, the bone itself will offer no resistance to perfect reposition. And I also assert, that if he does not succeed in re-establishing the original form of this canal, the use of any splints of whatever kind, secured by whatever means, whether elastic or non-elastic, are contra-indicated in the case. I never depend upon the pressure of a splint to do the work which I should do myself, although I recognize their usefulness in reinforcing by gentle and equable pressure the coaptating function of the soft tissues. Perfect coaptation, I am aware, is not in every case obtainable, by whatever means he may employ, but in cases where perfect reduction cannot be effected, extreme care and excellent judgment on the part of the surgeon in the use of splints is indispensable.

In preparing a fractured femur for extension, I am careful to carry my adhesive side plasters, Fig. 2, up to the seat of the injury, so that no undue traction may be brought to bear upon the knee joint.

Many surgeons terminate these strips below the knee. I prefer the other method. It is an interesting fact, gentlemen, that Hippocrates, nearly five centuries before the Christian era, recommended extension for the rectification of all deformities produced by fracture and dislocation of this bone. $\mathrm{He}$ advises " extension in as straight a manner as possible, so that the fragments may unite properly." $\mathrm{He}$ also says that " it is a great disgrace to the physician to exhibit a shortened thigh."

It is probably right, then, that we should give him the credit for the introduction of this valuable principle. And as he does not say much ahout his methods of application, we are by no meaus certain that he did not use Desault's, Liston's, Buck's, and all the other plans with which you are familiar, including even those offered by your humble servant on this occasion, never dreaming that these great surgeons would re-invent them and get the credit for them all down through future ages. I should mention that I never use a long-side splint. Sometimss, however, a board like a long splint may be fastened to the body and limb to restrain movements. This 
can also be effected by a piece of muslin a foot wide, one end being pushed under the hips of the patient from the injured side, and the other over his bodyboth ends being fastened to the opposite bed-rail. This is more easily worn by the patient, and also answers the purpose of preventing all tendency to yield to the extending force. When the patient has recovered sufficiently to leave his bed, crutches are found to be necessary to enable him to move about for exercise and for other purposes; and if you look at Plate VI you will see a good representation of a saddle-crutch which I invented some time since, and which has given a number of my patients a great deal of comfort and myself much satisfaction. The saddle and suspenders are worn inside of the clothing, the hooks alone coming out two inches below the axillæ. Ordinary sticks of proper length suit quite well for crutches if the top end is chiseled to fit the hooks of the suspenders, as they do not touch the axilla when the patient is suspended upon them. Thus the body can be maintained in a natural posture both while standing on the feet, while sitting on a chair, and while swinging in the act of stepping. will mention two cases:

Mrs. G., a lady of two hundred and ten pounds weight, came under my care last winter with fractured fibula. When the proper time had arrived I ordered crutches, as usual. Their use was attended with so much suffering, she being afflicted with prolapsus uteri, that she was indisposed to take necessary exercise.

I then had a saddle prepared for her, and nicely padded to fit. This she used during the period of convalescence without discomfort walking three or four hours every day. After she gave up using it, it was re-covered with soft leather and sent to me. It had proved such a pleasant support for her that when her limb was quite restored to usefulness she abandoned the use of the saddle with regret. I pass it round that you may see how it is padded to suit the circumstances.

Mr. B., a gentleman of two hundred and thirty pounds weight, with a similar injury. On the ninth day he procured a pair of crutches, but he got along rather poorly with them. I lent him a saddle, and from that time until he got quite well he used it constantly. It is not necessary for me to explain the advantages of carrying the weight of the body upon well-cushioned pelvic bones fitted by nature for the purpose. Neither do I feel called upon to point out the inconvenience and suffering imposed upon a patient when the doctor orders him to take exercise with ordinary crutches, with the weight of his body suspended upon cross-heads in the axillæ, where he is also in constant danger of injury to the vessels and nerves contained within their boundaries. These are obvious to you all without further mention. The saddle is of simple construction, and can be made very cheaply. I use a bit of steel plate cut to shape and bended into the general form of a saddle. A few holes are drilled in it to fasten the padding, and a little rivet on each corner, with a protruding head like a button, to fasten the suspenders to. The straps and hooks can be made of any material that is strong enough to carry the body and to suit the pocket or taste of the wearer. I use the boot-strap webbing one inch wide, with button hole on one end and a buckle near the other end, so that they may be shortened or lengthened at pleasure. Leather straps answer the purpose. The hooks can be made of thick wire bended to suit. I use thin steel plate cut to shape and bended as required.

FRACTURE OF RIBS.

The diagnosis, where one or more ribs are broken, I do not often find very difficult to make. The ob. jective symptoms, as the patient stands before me, being quite sufficient, in a large majorityof cases, to lead to a correct conclusion. He exhibits more or less pleurosthotonos, with restrained movement on the injured side. Then there is more or less embarrassment of respiration. Often there is a tendency to slight but frequently recurring cough. And while he tries to suppress every movement, he finds this impossible. And it is evident that every unusually violent expiratory effort is attended by very acute suffering. This, we may conclude, is probably a case of fractured ribs, although it is still possible that a severe contusion might be accompanied by all these symptoms. His clothing is now gently removed. Inspection may or may not reveal any marked depression or bulging of any part of the thorax. The story of the injury is told. The part which received the full force of the blow is pointed out, and I now know pretty well what may have occurred to the ribs and also to the adjacent structures. But I desire to know what really has happened, and if fractures are present with resulting injury to the lung, pleura and other tissues and

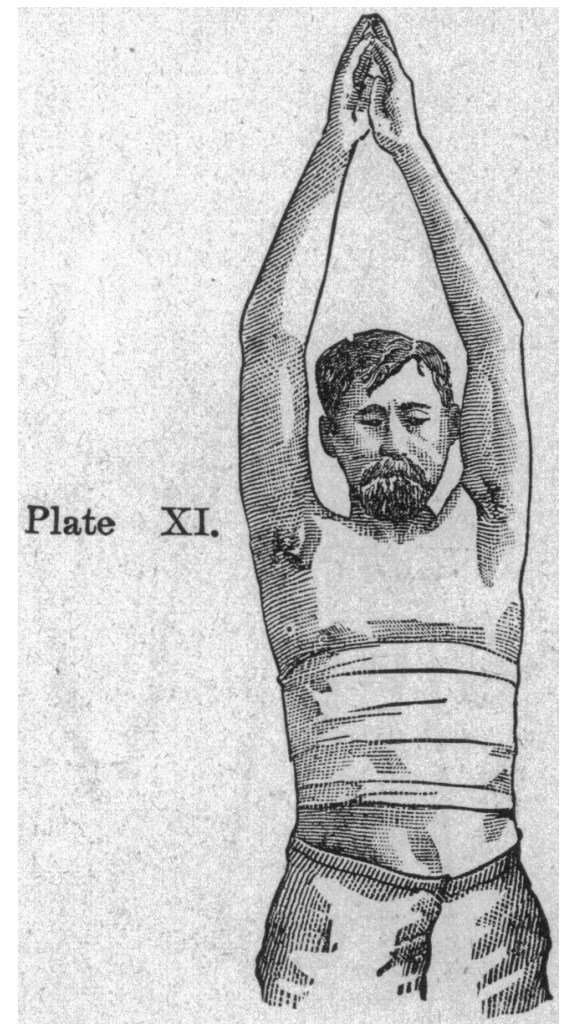


depression or bulging of fragments still persist, I desire to restore them to their original relations as quickly as may be and with the least possible addition to the sufferings of the patient consistent with the accomplishment of those objects. And if there are no fractures present, the course which I pursue will not be attended with any inconvenience. I generally succeed in proving my diagnosis without ever touching, even with my fingers, the affected parts. I subject him to a series of simple maneuvers which give him but little inconvenience, and which, in a few minutes, are attended by much relief of suffering, in most cases. If you look at Plate XI you will see that $I$ raise his hands as high as possible over his head, retain them there a minute or two, then let them down gently, and repeat these movements a number of times. This gives the intercostal muscles an opportunity to draw upon the fragments in the direction of replacement, being assisted by the pressure from within of a whole thoraxful of viscera and fluid, while outside every fiber of the thoracic muscles work in harmony with the same end in view, namely, replacement. Next, while his arms are still extended as high as possible-and it is sometimes necessary to give him assistance to maintain this position-I take a three-inch roller bandage and wind it firmly round the chest, covering an inch or two above and below the seat of the injury and secure it in place with a pin. Now I let his arms down. Usually, by this time, especially if the ribs have been fractured, the relief of his suffering is very marked. This is the case to some extent even in a simple contusion, as the parts are put at rest. I now give him a seat, throw his coat over his shoulders, and leave him a little while. An adhesive plaster band is now prepared, and in a half hour or so I am ready to ap-

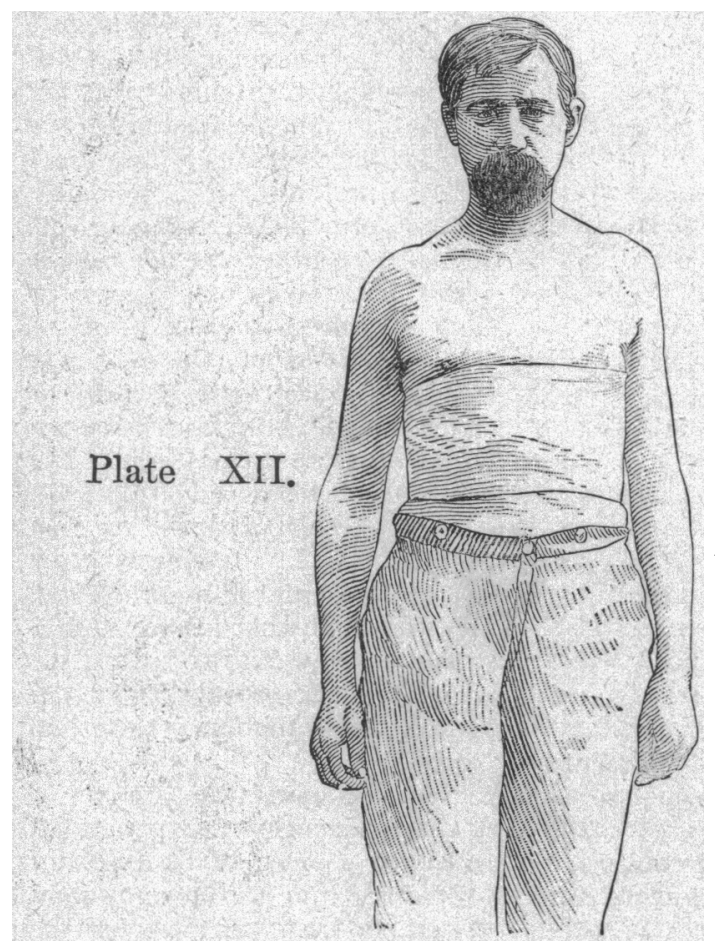

ply it. If my diagnosis was correct, he can now cough without much suffering, and he takes posture again as in Plate XI, while I remove the temporary roller. If the contusion has been severe I apply a belladonna plaster smoothly over the injured part. I then put on the adhesive band, and the dressing is complete, as shown in Plate XII. Now my diagnosis has been made with more or less satisfaction to myself. But the patient has been relieved, and is now hopeful again. And what does he care for a fine Latin diagnosis as he retires with grateful thanks upon his lips and a benediction in his heart.

In a few days he returns for inspection, and possibly readjustment of his bandage. The dressing should not be removed in less than four weeks.

\section{FRACTURE OF LOWER END OF RADIUS, KNOWN AS} COLLES FRACTURE.

The unsightly deformities at the wrist joint which result from improper treatment of this very common fracture, should make the surgeon very careful in his selection of the method by which he proposes to treat his case. The fact that he has followed a course which has been successful in the hands of distinguished members of the profession, will not justify him, in the eyes of his patient nor in a court of law, if his treatment should, unfortunately, result in a badly deformed arm, with greatly impaired function and constant and prolonged suffering. The method which has developed under my hands in the course of many years' practice, and having treated several hundred cases in my clinic in the out-door department of Bellevue Hospital, is very simple and inexpensive;

\section{Plate VII.}

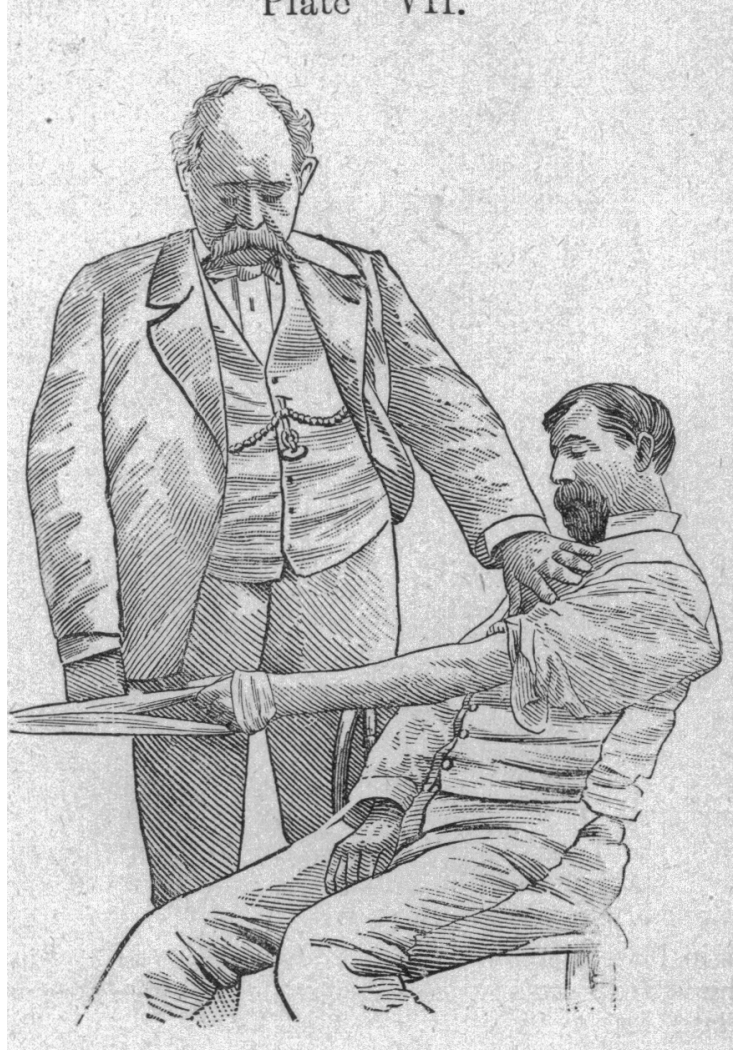


and, better still, I have never had a single resulting deformity, nor a case of persistent impairment of function, where it was a simple fracture.

The diagnosis in this fracture is also easily made, often a glance of the practiced eye of the surgeon being sufficient to settle the question, without any manipulation of the injured member. And as the patient is most likely suffering quite enough already, $I$ avoid as much as possible adding to his suffering by refinements of investigation, as my treatment will very likely be just the same whether the distal fragment be loose or impacted. If the accident has been of recent occurrence and there is but little swelling, the characteristic deformity is often quite apparent, and I seldom meet with much difficulty in making reduction by the method which I will now explain. I take a couple of yards of roller bandage, tie the ends together, making a loop; I lay the middle of the loop on the back of the hand; then crossing it in the palm, the patient grasps it with his fingers, as seen in Plate VII. I fasten the other end of the loop to a hook in the wall, a door-knob, or other convenient object. Now I set the patient on a chair sideways, and let him pull as much as he can ; an assistant sometimes helps him to do this, as seen in the engraving. Thus extension is made, and usually the pain is much diminished in a few minutes. I however leave him seated thus for fifteen or twenty minutes, or until the muscles are quite tired and relaxed; then with my fingers and thumbs I carefully replace the fragment,

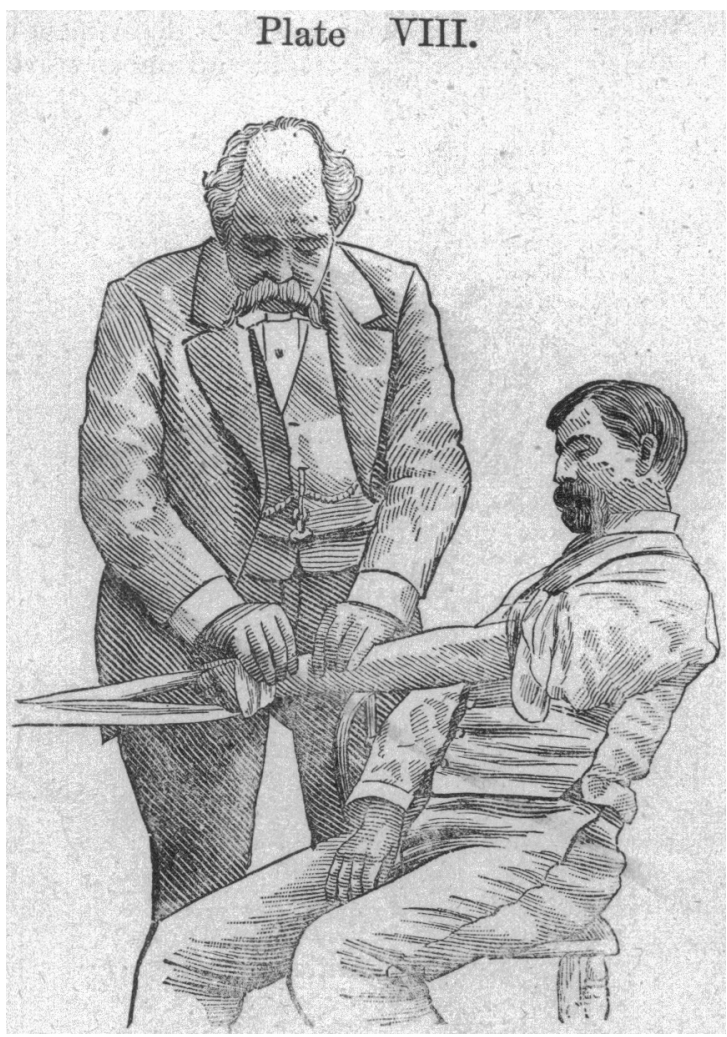

as in Plate VIII. When there is much swelling I use the vertical method of extension, for obvious reasons, Plates IX. A, X. A.

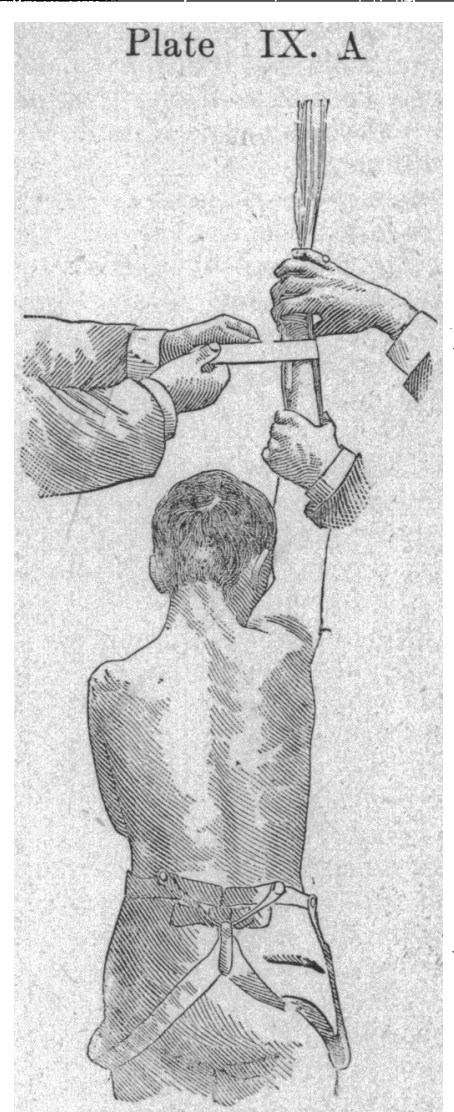

From this point the treatment is similar. My splints are very simple, made of thin wood a little wider than the arm, well padded with oakum or tow. I do not cover the padding as is generally done, as I find it easier to adapt them to the inequalities of surface without. 'The palmer splint reaches from the roots of the fingers to a little above the middle of the arm. I cut a place out for the ball of the thumb as it is not necessary to confine it with the splint. The dorsal splint reaches from the carpo-metacarpal articulation up to the same point on the arm as the other. When the splints have been nicely adjusted they are held in place by three strips of adhesive plaster an inch wide. I do not apply the plaster so tightly as to cause pain by pressure, as, if perfect coaptation has been effected, but little force is necessary to retain the distal fragment in position. But this is the point of the whole matter, reduction must be perfect or deformity will result, and the surgeon must not expect the splints to do by pressure what he has failed to do himself by careful manipulation when he could both see and feel what he was doing. I use no interosseous pads as they tend to spread the bones apart and thus increase the possibility of deformity, and besides there is no tendency to lateral displacement inwards.

I do not relax the extension until the dressing is completed. By that time generally the patient is pretty comfortable, and, with a piece of bandage for a sling, I let him go, directing him to return as soon as he feels that he should, so that I may tighten the 
splints to follow the atrophy of the soft tissues. I very seldom require to readjust them otherwise.
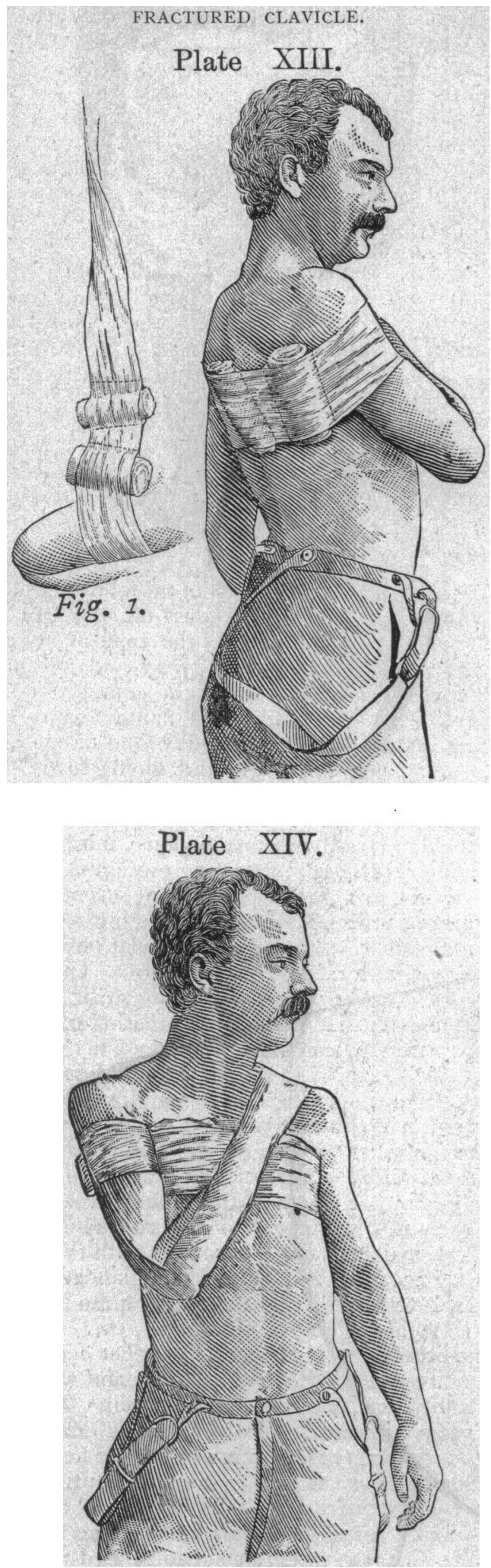

The diagnosis in this fracture is very simple. I think it unnecessary to say a word about it. When the clothing is removed we see that the arm droops downward and forward, and often the distal end of the sternal fragment is felt by the finger sharply defined under the soft tissues-often both fragments may be felt and crepitus may be easily produced by those who like such music. I do not and I never try to produce it until I have exhausted all other means of investigation. Now let us dress the case.

I recognized early in my practice the necessity of making the scapula as nearly as possible a fixture while treating a fractured clavicle, as the weight of the arm drags the acromial end downwards and the attached fragment of the clavicle goes with it, so that it requires some means of not only restoring the normal relations of the parts, but it is necessary to hold them in place during the entire period required for the reparative processes. - And I think, gentlemen, that want of attention to this point will account for a very large proportion of the failures to cure this injury without deformity. I use an adhesive bandage, say four inches wide. One end of this is reflected upon itself, forming a long loop, Fig. I. This bandage is long enough to encircle the body. I place a large roller-bandage in the loop, leaving room for the arm, and secure with pins. When ready to dress the case I slip the loop over the hand and up over the insertion of the deltoid muscle, and well up in the axilla, the roller being far enough from the arm to admit the fingers. It may even be placed against the outer border of the scapula, although that is not necessary, as there is not much tendency to displacement of this bone forwards. I now place a smaller roller, say one inch in diameter, in the loop opposite the inner border of the scapula, and corresponding to it in angle, and fasten it there, so that when the outer part of the adhesive bandage is brought to bear firmly upon and around the thorax, mischievous movements on the part of the bone are impossible. Before applying that part of the dressing permanently I raise the injured shoulder, keeping the elbow upon the lateral median line of the thorax, and secure this position by the adhesive bandage. I then take a strip of adhesive plaster, four inches wide, and long enough to reach. I cut a slit in it, placing a few folds of lint over the slit. That I place under the olecranon process, then carry the plaster up on the arm and and hand. Now I bring the arm forward in front of the body with some force as a lever. The loop bandage being the fulcrum, and thus the acromial fragment is forced outwards, and generally the bone will of itself resume its normal form and relations under this maneuver. My plaster is now carried over the shoulder of the sound side and the hand is thus secured firmly. The other end of this bandage is now carried up the dorsum of the arm and adheres to the opposite shoulder. Now the dressing is complete, although for the additional comfort of my patient, I usually cover this dressing with a nice roller bandage, applied over all. The advantages which I claim for this method are, first, I do not ligate the arm, as there is plenty of room left between the roller and the arm to prevent unpleasant embar- 
rassment of the circulation, and, second, I secure immobility of the scapula, or nearly so, adding much to the chances of cure without deformity.

My dressing of this fracture looks not unlike that used by many other surgeons. But its true inwardness and essential differences are easily found on inspection. I have treated a very large number of cases of fractured clavicle by this method, and my results will compare favorably with those of any other surgeon within my knowledge. Other fractures I must leave for future opportunity.

\section{EXSECTION OF BOTH HIP JOINTS FOR MORBUS COXARIUS.}

BY WILLIAM A. BYRD, M.D., OF QUINCY, ILLINOIS.

[Read before the Surgical Section of the Am. Med. Association, June, I883.)

Ever since the first suggestion of the removal of the head of the femur by Mr. Charles White, in 1769 , for morbus coxarius, and the execution of it first by Schmalz, in 1816, as stated by Dr. Sayre, Anthony White, in r822, as claimed by Barwell, there has been great diversity of opinion among surgeons in regard to the propriety of this operation, a few favoring, and many, condemning it as being entirely useless, claiming that even when it succeeded in saving the life of the patient, it left a miserably deformed being unable to walk without the aid of crutch or cane, and the chances of cure were no greater than if the patient was allowed to depend upon the slow process of spontaneous exfoliation of the diseased bone, a process which was rarely accomplished before the death of the patient. Opinions have greatly changed since the excisions have become numerous enough to compare with the older method. A condition brought about by various operators, and given a great impetus by Dr. L. A. Sayre, who claims the recovery of sixtythree out of seventy-two excisions of the joint. The gravity of a single excision having been considered so great, I presume but few surgeons thought there would be any propriety whatever in double excisions, though, of course, subjects requiring double excision present but seldom. I have found a record of but two cases of the kind, which you may find in the last edition of Dr. John Ashhurst, Jr's. "Surgery," p. 633. He writes: "I once had occasion to resort to excision of both hip-joints, the result (fig. $3^{16}$ ) as regards life, was satisfactory, but the patient was not able to walk without crutches as long as he remained under my observation. A similar operation has since been performed by Mr. Croft." Now the case I have the honor to report to you is not only able to walk without crutches, but she goes up and down stairs very well without them, and attends school every day. When passing over rough ground she makes use of the crutches; traversing smooth places, without them. The accompanying photograph shows the appearance of the parts after the excision.

I will now read you a carefully written account of her condition previous to the excision, by Dr. Moses F. Bassett, a gentleman highly respected in our city:

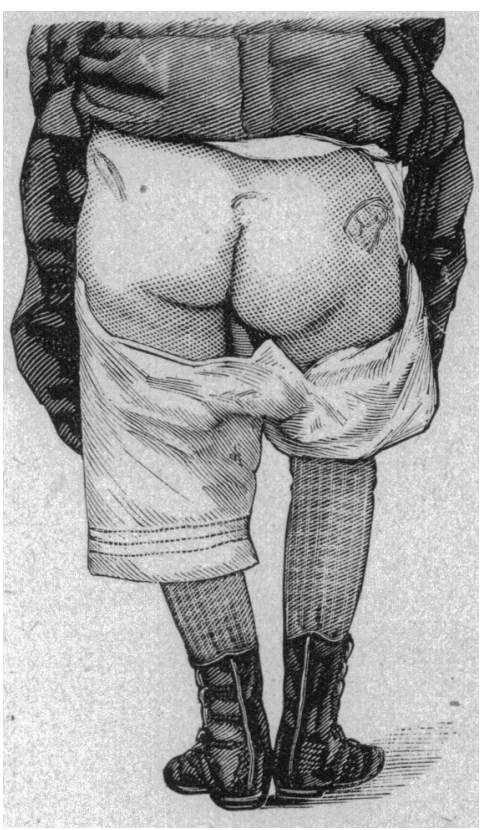

"Susie Mahaffey, the subject of the following sketch, was born in Quincy, Ills., August Ist, I 873, of Irish parentage on both sides. At the time of her birth her father was aged sixty-five years and her mother thirty-one. The child has light complexion, pale blue eyes, flaxen hair and is of flabby texture; is of a bright, cheerful disposition, very fond of music and precocious, both physically and intellectually. She first came under my observation in February, 1876. She then had masses of enlarged lymphatic glands in the cervical and submaxilary regions, and the parotid gland of left side was suppurating profusely. She had been in this, or a similar condition, several months, and was markedly anæmic and suffering with hectic. Several irregular, and lately one regular physician had treated her with no apparent benefit. The last one had told her parents she had "King's evil," and was incurable. After a careful examination of the case, and by urgent solicitation, I undertook her treatment. I enjoined cleanliness, nutritious and abundant diet, exercise in the open air, by being drawn in a baby wagon, and gave alteratives and tonics, both mineral and vegetable, including potass. iodide. sulph quin. sassaparilla, stillingia, iron, etc.; also cod-liver oil; topically used salicylic, carbolic and benzoic acids, zinc and iodoform, and had the satisfaction of discharging her in about six months, with the abcesses healed, the enlarged and indurated glands reduced to normal size, nutrition good, getting quite fleshy, and with rosy cheeks.

From the autumn of I 876 I saw her occasionally, always looking bright and healthy, and was told by her family that she was perfectly well. More than five years afterward, on the night of March $15^{\text {th }}$, I 88I, I was urgently summoned to see her, and was told she had been sick in bed with a continued fever for six weeks, under the care of one of her former physicians; that she was now in a dying condition, and the doctor in attendance had refused to treat her 